\title{
MONGOOSE-Monitoring Global Online Opinions via Semantic Extraction
}

\author{
S. Haritha \\ UG Scholar, Department of \\ Computer Science \& \\ Engineering, \\ St.ANN'S College of \\ Engineering \& \\ Technology, Chirala, A.P, \\ India.
}

\author{
Y. Anusha \\ UG Scholar, Department of \\ Computer Science \& \\ Engineering, \\ St.ANN'S College of \\ Engineering \& \\ Technology, Chirala, A.P, \\ India.
}

\author{
P. Sai Avinash \\ UG Scholar, Department of \\ Computer Science \& \\ Engineering, \\ St.ANN'S College of \\ Engineering \& \\ Technology, Chirala, A.P, \\ India.
}

\author{
S.V. Manikanta \\ UG Scholar, Department of \\ Computer Science \& Engineering, \\ St.ANN'S College of Engineering \& Technology, \\ Chirala, A.P, India.
}

\author{
Ch. Vijayananda Ratnam \\ Assistant Professor, \\ Department of Computer Science \& Engineering, \\ St.ANN'S College of Engineering \& \\ Technology, Chirala, A.P, India
}

\begin{abstract}
"MONGOOSE" is a strategy which separates client assessments that are executing this method for web shopping webpage gives data about best items in all fields like dresses,mobiles,jewellery and blessing articles based upon client rating and conclusion. It is relies on upon the client assessment to include or evacuate the items in our Website. In this data is accumulated for nothing and open sources on the web as often as possible integrated.This is a methodology that looks to lessen the time spends on making a steady information. It lessens an ideal opportunity to-effect of cutting edge investigation administration arrangements. Consumers are often forced to wade through an alarming number of online reviews in order to make an informed product choice .This paper introduces opinion extraction, an unsupervised information-extraction system that mines product reviews in order to build a model of important product features, their evaluation by reviewers, and their relative quality across different product instances. When compared to previous work, it achieves $22 \%$ higher precision (at the cost of 3\% lower recall) on feature extraction. In addition, it reports an $8 \%$ improvement in accuracy on the task of determining whether an opinion sentence is positive or negative. OPINE's success comes from a more comprehensive effort to identify product features, which enables it to augment review opinions with background information extracted from the Web.
\end{abstract}

\section{Keywords}

opinionmining,webextraction,textmining,SemanticExtraction, DataMining

\section{INTRODUCTION}

In a couple web shopping local people like filpkart , amazon... customer can give rating before using the thing. In this customer can buy the things shockingly login and he/she can login for the secondtime then our endeavor approaches us for give rating and supposition for the last thing then customer can without quite a bit of a stretch give the contribution about the thing. we show an information searching for candidly steady system - MONGOOSE (MONitoring Global Online Opinions by method for Semantic Extraction) - that addresses this imbalance. It should be seen that regardless of the way that MONGOOSE was made to fulfill the necessities saw similarly as we can tell with web-scale examination organization systems, for instance, WebFountain SoundIndex etc, it has in like manner been successfully associated with various non-web content spaces, for instance, multi-secluded burrowing for restorative administrations candidly steady networks, corporate exchanges examination, and casual group examination. Despite showcasing the extensive fittingness of an unstructured ETL instrument, for instance, MONGOOSE, these associations display the connection and-play point of view that grants structure creators to rapidly grasp and modify specific portions of MONGOOSE to pass on complete systems to customers in advance phenomenal time ranges. This paper is sorted out as takes after showcases an audit of the MONGOOSE system. Purposes of enthusiasm of the structure are shown. It highlights the key duties of MONGOOSE, while it centers to related work around there. Game plans of MONGOOSE are indicated, and the completion of the paper and organized future work are shown mining is the computational investigation of individuals' assessments, evaluations and feelings toward substances, occasions and their characteristics.

It includes methods from various orders like data recovery, regular dialect preparing and information mining It is exceptionally testing to mine assessments from audits which are in characteristic dialect. Suppositions are important to the point that at whatever point one needs to settle on a choice, one needs to hear others' feelings. This is valid for both people and associations. On the off chance that an individual needs to buy an item, it is helpful to see an outline of suppositions of existing clients so that he/she can settle on choice. This is superior to anything perusing an expansive number of audits. $\mathrm{He} / \mathrm{she}$ can likewise think about the outlines of feelings of various items, rather than perusing countless. Utilizing conclusion mining an audit can be assessed at three distinctive levels-at record level, sentence level and highlight level. At the point when survey is assessed at record level, entire audit is grouped into either positive or negative contingent on the supposition communicated in that audit. At the point when 
audit is assessed at sentence level, then every sentence in a survey is characterized into either positive or negative. Though highlight level or highlight based assessment mining gives outline which highlight of item is enjoyed or disdained by commentator. Report level assessment mining think about as a basic content characterization issue. It is additionally called as Sentiment Classification. Highlight based supposition mining and rundown can't be considered as content grouping issue. How include based conclusion mining and outline should be possible is examines in this paper. This paper is sorted out as tails: It talks about component level supposition mining and rundown and some essential strides for sit, It focus on various methodologies proposed by specialists, examines execution measures.

\subsection{Database}

Database is an accumulation of information with the goal that client can without much of a stretch be gotten to and upgraded. The information is normally in a manner that backings forms requiring data. A Database administration framework is a PC programming that cooperates with the client and different applications , and the database itself to break down information. In our database we are putting away the information identified with the items rating and assessments and exchanges.

\section{RELATED WORK}

In exiting system, we need to spend a tremendous measure of time,effort and assets Because the current framework getting to be harder furthermore takes sufficient of time to pursuit and purchase.In existing framework client can give the rating before the item buying or using.Ex:- If client can hunt down REDMI mobiles then it will show all the models of REDMI mobiles then it excessively harder, making it impossible to buy via looking the items furthermore take plentiful of time.

\section{PROPOSED WORK}

In proposed system we built up an application named "MONGOOSE" with the goal that client can without much of a stretch hunt and buy item as per the client rating and supposition. In this paper we are executing that client can give the criticism and rating in the wake of acquiring and utilizing the item. It fulfills the necessities of the web clients and enhance the clients involvement in numerous web applications

\section{SYSTEM ARCHITECTURE}

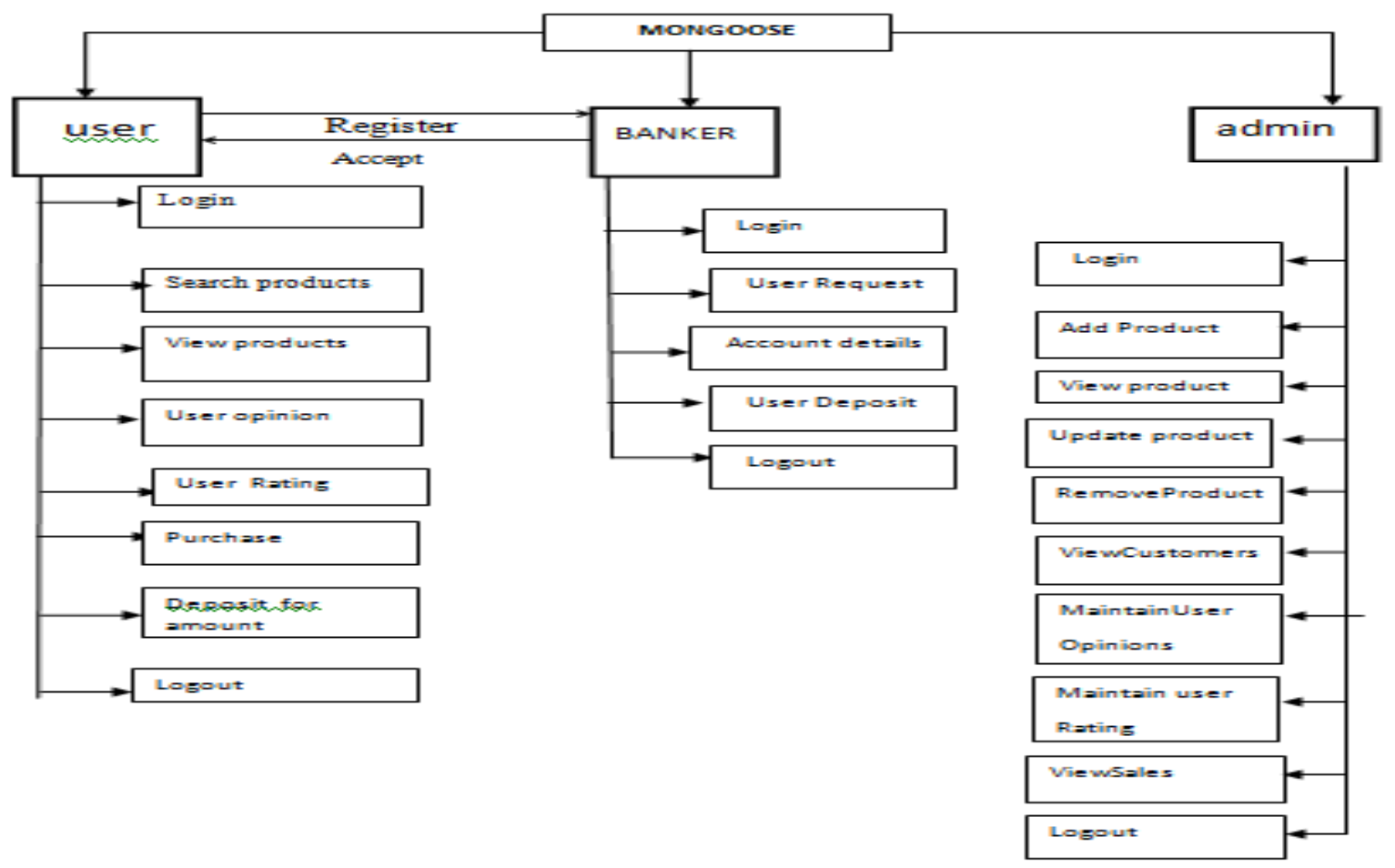

Figure.1

\section{IMPLEMENTATION OF PROPOSED WORK}

\subsection{Modules}

In our project we have three modules named User, Admin and Banker.

\section{Admin}

The main role of ADMIN is to add products in the site and if any products are not sold by any one that are removed from site and update the new products, view the customer sales and also maintain the user opinion and ranking.

Banker

It Accept user registration request and maintain transaction.

User

Comparison shopping and product selection on various attributes in terms of price and placement of order and authorization of payment.

\subsection{Procedure}

\section{1) Registration}

This module provides the user to register himself/herself on the website by providing proper details it will provide the common and unique ACCOUNT NUMBER and CUSTOMER ID 


\section{2) Banker login}

After registration the banker can login with the Username and password. In this module banker can accept the user request after accepting request user can login with the customer id and password. In this banker can maintain transactions.

\section{3) Admin login}

The admin logins to view the requests from the user. Based on proper verification he would be accepting or rejecting the requests and also view the number of users registered along with the opinions and ratings .In this admin can add products, view products, view customers, update and remove products. It also maintain user rating and opinions.

\section{4) Logout}

After Buying and rating the product user can logout.After updating the product admin can logout.And after completing transactions banker can logout

\section{RESULTS}

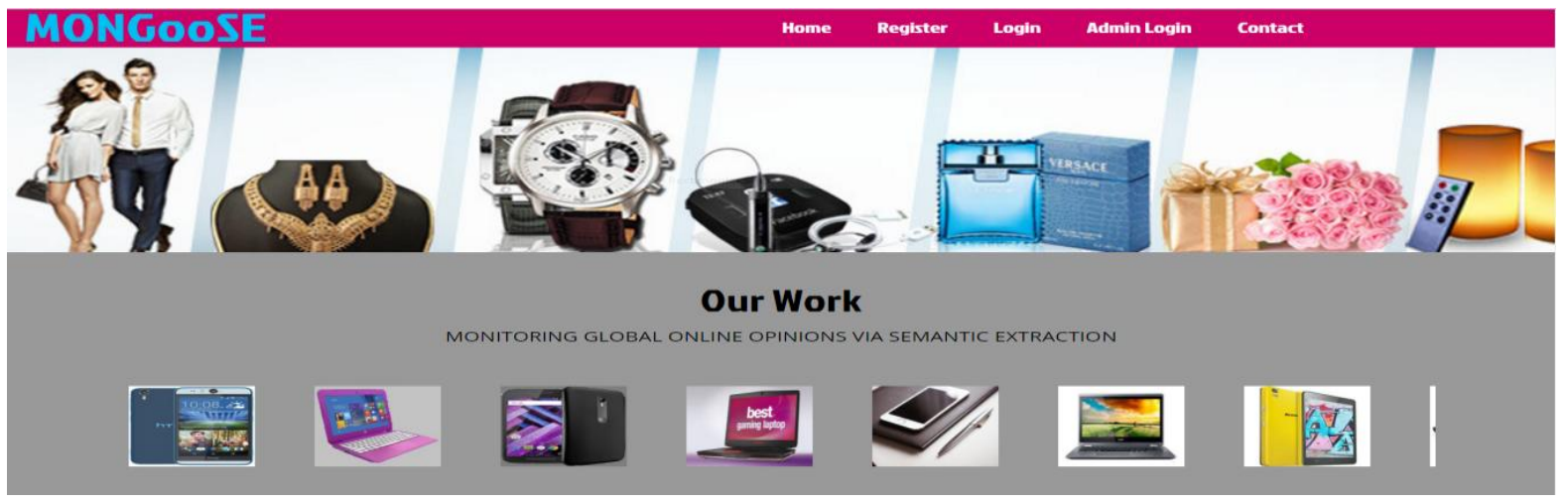

Figure.2 Home Page: This is our homepage for user

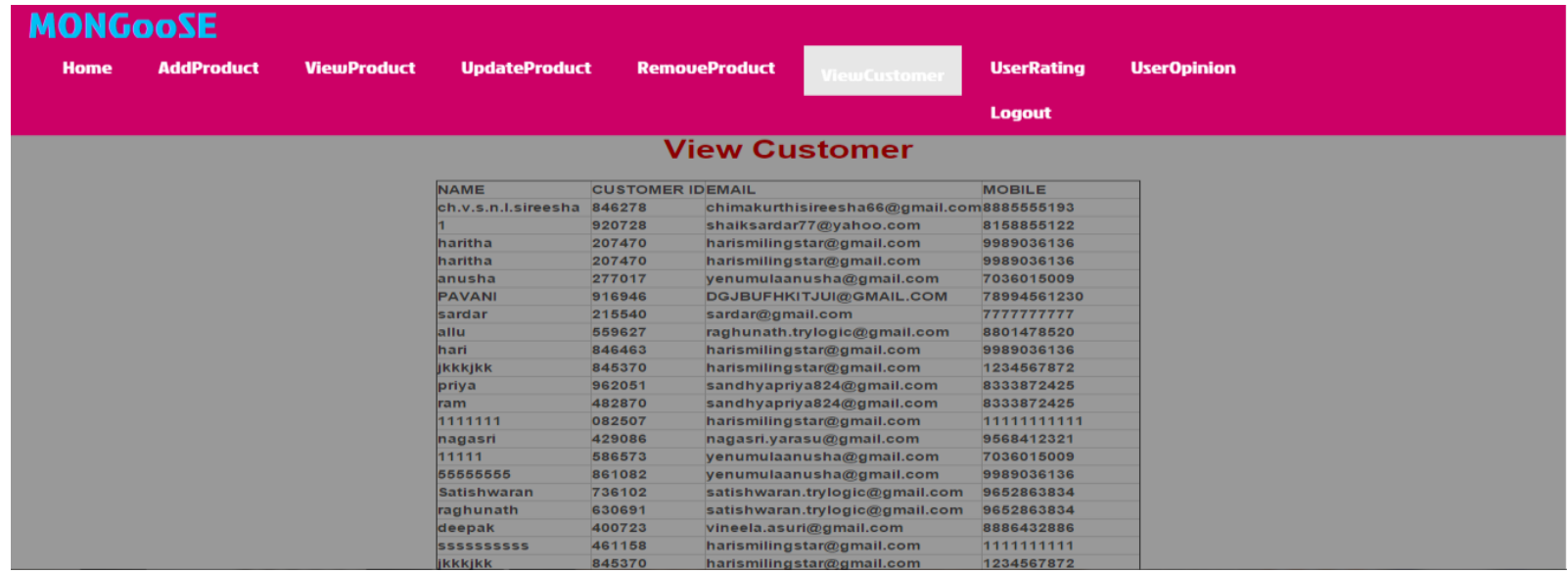

Figure.3 Admin View Customer: In this Admin can see how many customers buy the products.
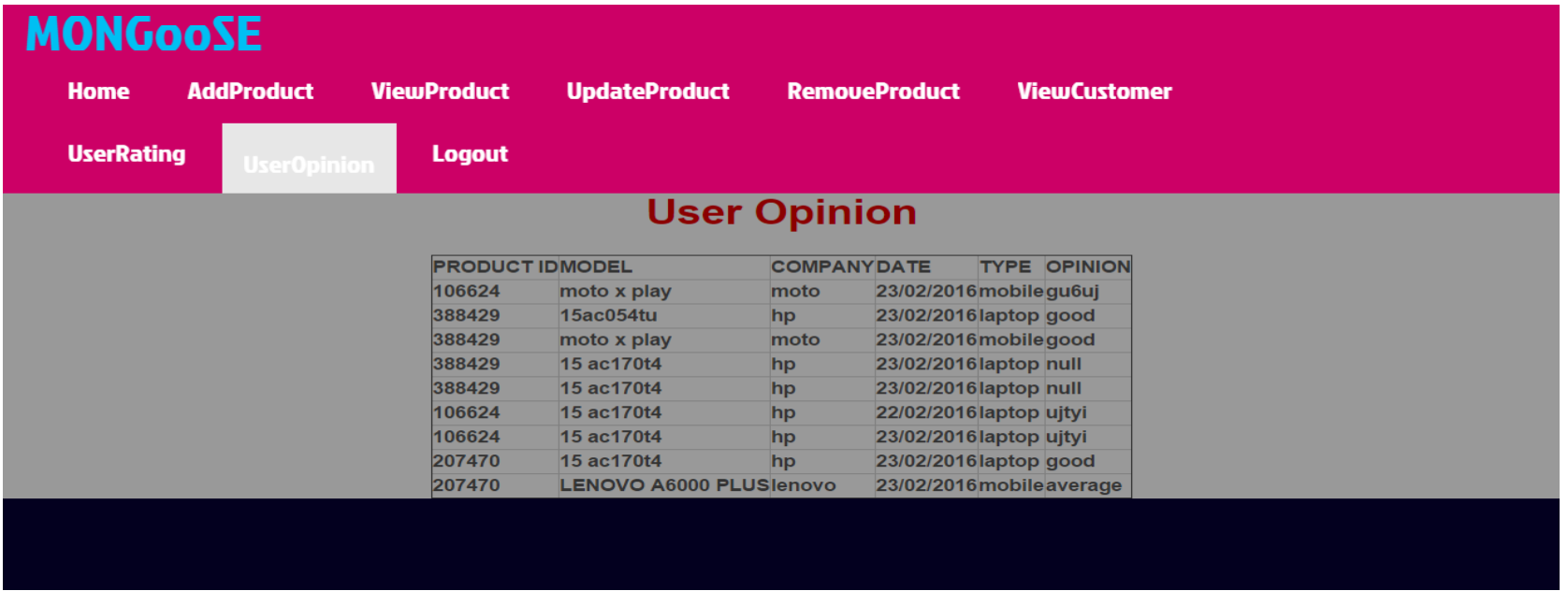

Figure.4 Admin user opinion: Admin maintain user opinions 


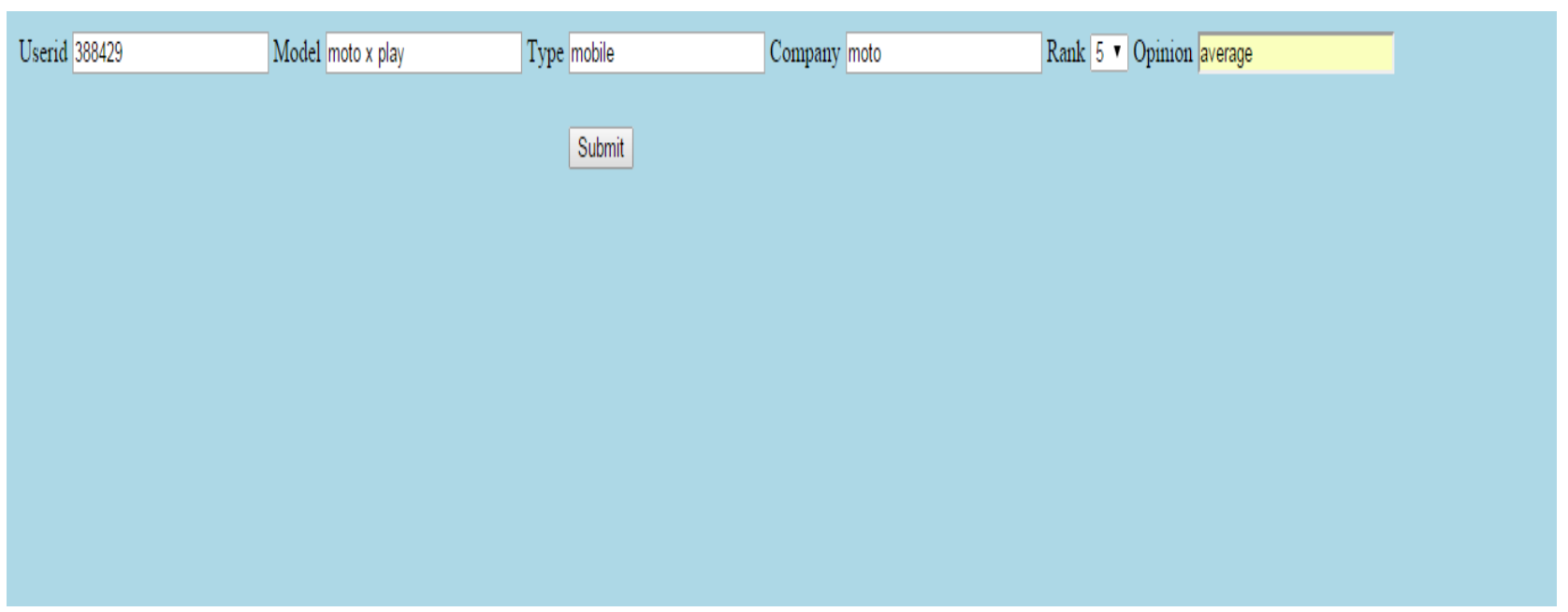

Figure.5 User Rating: This is user rating users can give rating and opinion about the product.

\section{CONCLUSION \& FUTUREWORK}

We develop an application for that user can give correct opinions about the used products and also give rating to those products. We can easily find out the best products as per the user ratings. At first time login user can purchase the product and for the next time login user can give the rating about the last product. So the users can give exact rating and opinions about that product.In addition to this, we plan to develop MONGOOSE for other domains to continue building on the domain cartridges. In future here we are implementing the credit card system so that every time user cannot request the amount from bank.

\section{REFERENCES}

[1] Alba, A., Bhagwan, V., and Grandison, T. 2008. Accessing the deep web: when good ideas go bad. In Companion To the 23rd ACM SIGPLAN Conference on Object-Oriented Programming Systems Languages and Applications (Nashville, TN, USA, October 19 - 23, 2008). OOPSLA Companion '08. ACM, New York, NY, 815-818.

[2] Chang, F., Dean, J., Ghemawat, S., Hsieh, W.C., Wallach, D.A., Burrows, M., Chandra, T., Fikes, A., Gruber, R.: Bigtable: A Distributed Storage System for Structured Data (Awarded Best Paper!). OSDI 2006: 205-218.
[3] Dean, J., Ghemawat, S.: MapReduce: Simplified Data Processing on Large Clusters. OSDI 2004: 137-150.

[4] Ferrucci, D. and Lally, A. 2004. UIMA: an architectural approach to unstructured information processing in the corporate research environment. Nat. Lang. Eng. 10, 3-4 (Sep. 2004), 327-348. Gruhl, D., Chavet, L., Gibson, D., Meyer, J., Pattanayak, P., Tomkins, A., and Zien, J. 2004. How to build a WebFountain: An architecture for very large-scale text analytics. IBM Syst. J. 43, 1 (Jan. 2004), 64-77.

[5] Zakharian, Z., Mishra, M., Chandramohan, S. "Cars 2.0". Masters Thesis, San Jose State Univeristy, December 2008.

[6] AALIM,http://www.almaden.ibm.com/cs/projects/aalim/ . Castero, M and Liskov, B. "Practical Byzantine Fault Tolerance". Operating Systems Design and Implementation Feb 1999.

[7] Varun Bhagwan, Tyrone Grandison, Daniel Gruhl, "Sound Index: Music Charts By The People, For The People". To appear in Communications of the ACM. September 2009. Vol 52, No 9.

[8] Yaukey, John. Feds test new dataminingprogram.USA Today.http://www.usatoday.com/news/washington/200703-07-datatools_N.htm. March 7, 2007 